\title{
Endoscopic laser treatment of diffuse gastric antral vascular ectasia
}

\author{
S Potamiano, C R Carter, J R Anderson
}

\begin{abstract}
Eight patients (six women and two men) were found to have iron deficiency anaemia due to diffuse gastric antral vascular ectasia. The mean age of the patients was $\mathbf{7 4 . 6}$ years (range 57-83). All required repeated blood transfusions (mean 18 units/year) before treatment. Five patients were classified as having the 'watermelon stomach' (group A) and three the 'honeycomb stomach' (group B), according to criteria described in previous reports. All were treated using neodymium:YAG laser photocoagulation. Significant endoscopic improvement and reduction in blood requirements were noticed in group $A$ in which only one patient required a transfusion after treatment. Results in group B were disappointing. One patient was operated on and the other two still require blood transfusions. Laser treatment was safe in both groups and no major complications were encountered.

(Gut 1994; 35: 461-463)
\end{abstract}

Diffuse gastric antral vascular ectasia (DGAVE) has been described in several reports ${ }^{12}$ but has received more attention since the classic study of Jabbari et al in 1984 who coined the term 'watermelon stomach'. ${ }^{3}$ This term was applied for the endoscopic description of longitudinal antral folds, containing visible vessels, radiating from the pylorus and resembling the skin of a watermelon. Although this is the most common endoscopic appearance, in some patients, DGAVE looks different. This led Chawla $e^{2} \mathrm{al}^{4}$ to distinguish three macroscopic patterns: (1) the most common, described above as the watermelon stomach; (2) the second most common appearance is characterised by many angiodysplastic lesions that seem to coalesce, forming a giant red lesion, resembling a honeycomb; (3) the least common variety resembles a large flat mushroom, characterised by an isolated, slightly raised, and well demarcated lesion formed by a tuft of ectatic vessels. ectatic lesions; and the honeycomb stomach $(B)$ with a more diffuse appearance of the ectatic lesions.
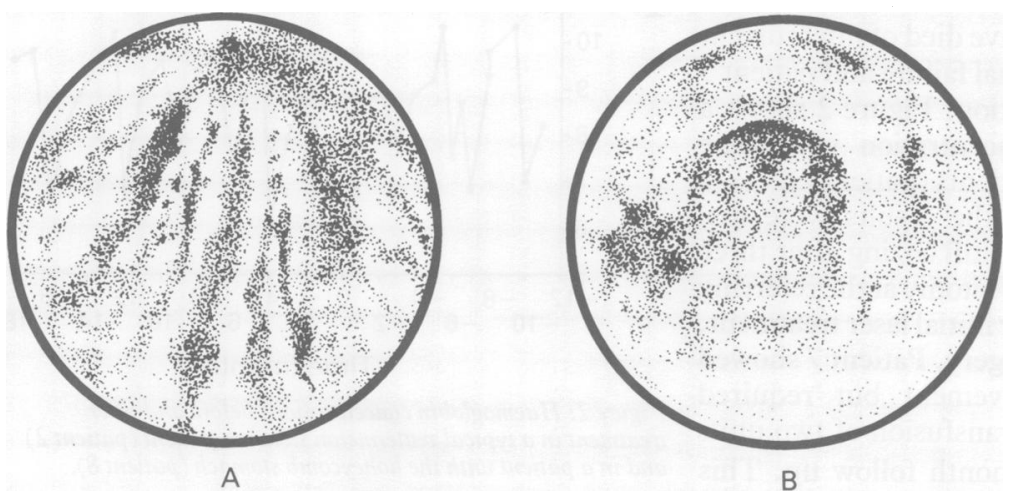

The condition is often misdiagnosed as antral haemorrhagic gastritis. ${ }^{356}$ Biopsies confirm the correct diagnosis with the characteristic features of hyperplastic surface mucosa with dilated and thrombosed capillaries and fibromuscular hyperplasia of the lamina propria with ectatic submucosal venous channels.

Although antrectomy offers definitive treatment of the condition, it carries significant short and longterm morbidity and an operative mortality of $5-10 \% .{ }^{78}$ Conservative treatment with blood transfusion, iron replacement, histamine $\mathrm{H}_{2}$ receptor antagonists, sucralfate, steroids, tranexamic acid have all be applied with limited success, in an attempt to balance the blood loss, or to diminish the severity of the bleeding episodes. ${ }^{238}$ Endostasis has also been used with varying results. ${ }^{59-14}$ In this report we describe eight patients with DGAVE, treated with the Nd:YAG laser focusing on the different therapeutic response of these patients according to their endoscopic pattern.

\section{Patients and methods}

PATIENTS

The mode of presentation, the blood transfusion requirements before and after treatment, the previous diagnoses, and the associated conditions of consecutive patients with DGAVE were prospectively recorded. The diagnosis was based on clinical history, endoscopic appearances, and characteristic histological findings.

Patients were classified into two groups according to their endoscopic pattern using the criteria proposed by Chawla et al. ${ }^{4}$ Group A consisted of patients with the classic watermelon stomach and group B consisted of those patients with the honeycomb stomach (Fig 1).

\section{LASER TECHNIQUE}

Patients were sedated with intravenous benzodiazepines and photocoagulation of the lesion was carried out with a Nd:YAG laser (Fibrelase 100, Living Technology, Glasgow, UK). The power setting for photocoagulation was $60-80$ watts and the pulse duration 0.5 to 1 second, delivering $30-80$ joules to the tissue. For the watermelon stomach, the lesion was treated beginning at the pylorus and proceeding proximally along each of the erythematous folds. The honeycomb stomach was started again as close to the pylorus as possible treating each quadrant in turn. The immediate visual effect was blanching of the irradiated area and minor oozing. Patients were treated at 2-3 weekly intervals. Histamine $\mathrm{H}_{2}$ receptor antagonists were routinely given after laser treatment for one month to avoid 


\begin{tabular}{|c|c|c|c|c|c|c|c|c|c|}
\hline Case & Age & Sex & $\begin{array}{l}\text { Bleeding } \\
\text { (months) }\end{array}$ & $\begin{array}{l}\text { Pretreatment } \\
\text { transfusion }\end{array}$ & Diagnosis & Association disease & $\begin{array}{l}\text { No laser } \\
\text { sessions }\end{array}$ & $\begin{array}{l}\text { Follow up } \\
\text { (months) })^{\star}\end{array}$ & $\begin{array}{l}\text { Post- } \\
\text { treatment } \\
\text { transfusion }\end{array}$ \\
\hline $\begin{array}{l}1 \\
2 \\
3 \\
4 \\
5 \\
6 \\
7 \\
8\end{array}$ & $\begin{array}{l}83 \\
81 \\
77 \\
76 \\
57 \\
76 \\
82 \\
65\end{array}$ & $\begin{array}{l}\mathbf{F} \\
\mathbf{F} \\
\mathbf{F} \\
\mathbf{F} \\
\mathbf{M} \\
\mathbf{M} \\
\mathbf{F} \\
\mathbf{F}\end{array}$ & $\begin{array}{l}9 \text { IDA(H) } \\
7 \text { IDA(M) } \\
6 \text { IDA } \\
6 \text { IDA(M) } \\
12 \text { IDA } \\
24 \text { IDA } \\
12 \text { IDA } \\
12 \text { IDA }\end{array}$ & $\begin{array}{r}13 \\
19 \\
16 \\
8 \\
18 \\
29 \\
11 \\
18\end{array}$ & $\begin{array}{l}\text { Watermelon } \\
\text { Watermelon } \\
\text { Watermelon } \\
\text { Watermelon } \\
\text { Watermelon } \\
\text { Honeycomb } \\
\text { Honeycomb } \\
\text { Honeycomb }\end{array}$ & $\begin{array}{l}\text { IHD } \\
\text { IHD } \\
\text { IHD } \\
\text { CRF, AS, COAD } \\
\text { IHD, PVD, haemophilia } \\
\text { IHD, CRF } \\
\text { IHD } \\
\text { PBC }\end{array}$ & $\begin{array}{r}3 \\
3 \\
4 \\
3 \\
3 \\
3 \\
8 \\
10\end{array}$ & $\begin{array}{c}44 \\
26 \\
19 \\
7 \dagger \\
18 \dagger \\
2 \ddagger \\
13 \dagger \\
27\end{array}$ & $\begin{array}{l}0 \\
0 \\
0 \\
2 \\
0 \\
7 \\
2 \\
24\end{array}$ \\
\hline
\end{tabular}

IDA = iron deficiency anaemia $(H=$ haematemesis; $M=$ melaena $) ; \mathrm{IHD}=$ ischaemic heart disease $\mathrm{CRF}=\mathrm{chronic}$ renal failure; $\mathrm{AS}=\mathrm{aortic}$ stenosis; $\mathrm{COAD}=$ chronic obstructive airways disease; $\mathrm{PVD}=$ peripheral vascular disease; $\mathrm{PBC}=$ primary biliary cirrhosis. $\star$ From first laser session; †died of intercurrent disease; †postoperative death (see text).

complications from any small iatrogenic ulcers that might develop.

\section{Results}

Eight patients (six women and two men) have been treated (Table). The mean age was 74.6 years (range 57-83). All had a history of severe iron deficiency anaemia and three had overt gastrointestinal bleeding. All required blood transfusions before treatment with an average of 18 units/year. Four patients were referred with an initial diagnosis of haemorrhagic antral gastritis. Five patients were considered endoscopically to have the watermelon stomach (group A) and three the honeycomb stomach (group B).

Patients in group A had a shorter bleeding history (mean eight months) than patients in group B (16 months) but yearly blood requirements were 22.5 and 14.5 units respectively. All three patients with overt gastrointestinal bleeding belonged in group $A$.

The number of laser sessions required for each patient depended on the clinical course and the endoscopic appearances. For group A patients, three or four sessions were sufficient. Although biopsy specimens after completion of treatment were not obtained, obliteration of the vascular pattern was seen in all group A patients. The endoscopic appearances returned to normal in two patients (patients 2 and 4 ). In patient 1 the final appearances were suggestive of atrophic gastritis. Patient 3 developed three superficial ulcers, which had healed with one months' treatment with histamine $\mathrm{H}_{2}$ receptor antagonists. Patient 5 had slight scarring on repeat endoscopy suggesting ulceration that had healed. Only one patient in group A (patient 4) required blood transfusion after the completion of laser therapy (two units) but this was probably attributable to renal failure rather than to the DGAVE. Two patients have died of intercurrent disease; patient 4 from renal failure and patient 5 from a myocardial infarction. Figure 2 shows a typical haemoglobin concentration with time curve for this group of patients (patient 2).

For group B patients the results were disappointing. Patient 6 was still oozing after three laser sessions and had antrectomy at the referring hospital, two months after initial laser treatment, and died 26 days after surgery. Patient 7 showed some endoscopic improvement but required eight laser sessions and transfusion of two units of blood during the 13 month follow up. This patient died from a bronchogenic carcinoma. Patient 8 again showed endoscopic improvement after 10 laser sessions but is still transfusion dependent (Fig 2).

There were no significant complications after laser therapy. Minor oozing that occurred during treatment was easily controlled with further laser therapy.

\section{Discussion}

Diffuse gastric antral vascular ectasia is a disorder primarily affecting elderly females, ${ }^{13}$ and as such the present group is in accordance with other studies. Although the cause of the condition is obscure, a number of coexisting diseases have been described possibly having an aetiological implication. The presence of ischaemic heart disease in most of our patients (six of eight) could be attributed either to the fact that some of them have been referred from other centres, considered unfit for surgery, or by a possible correlation of the vascular abnormalities with generalised atherosclerosis. ${ }^{7}$ It is presumed these
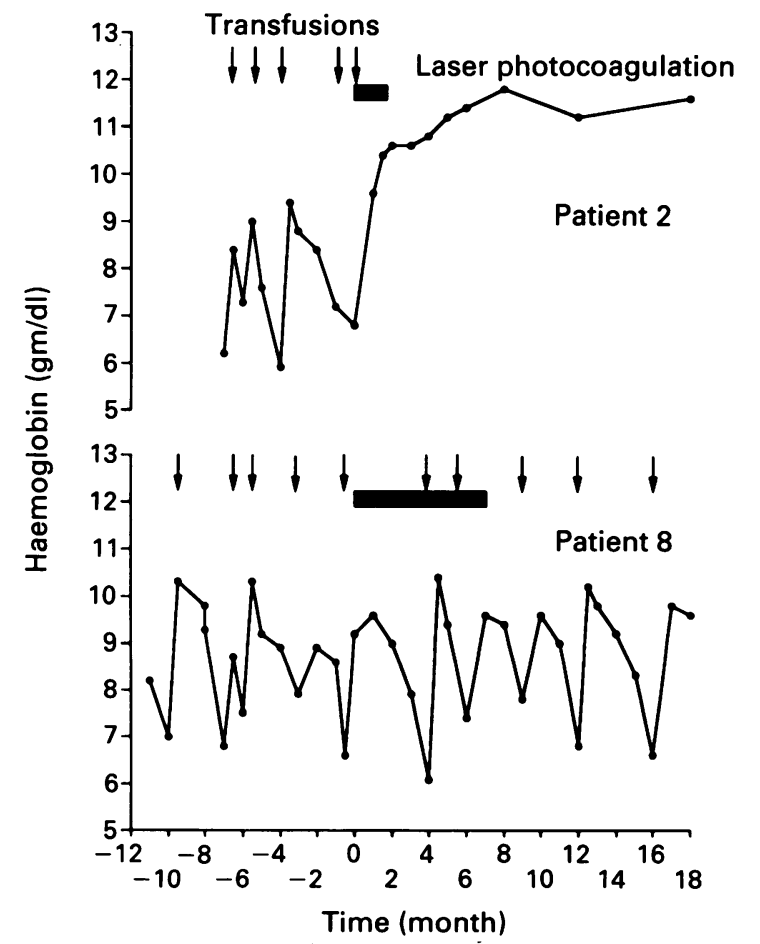

Figure 2: Haemoglobin concentrations before and after treatment in a typical watermelon stomach patient (patient 2) and in a patient with the honeycomb stomach (patient 8). 
lesions are related to chronic hypo-oxygenation of the microcirculation resulting from low cardiac output or decreased pulse pressure, or both as is found in aortic stenosis. ${ }^{4}$ The presence of DGAVE in patients with renal insufficiency has been reported in other studies ${ }^{43}$ and the association of renal insufficiency with angiodysplasia is well established. ${ }^{15}$ Two of our patients had chronic renal failure and this seems to be more than coincidental. The incidence of chronic liver disease in patients with DGAVE has been reported as high as $40 \% .{ }^{16}$ It has been suggested that the vascular lesion may be an example of portal hypertensive mucosal vasculopathy. ${ }^{16}$ We encountered only one patient with liver disease (primary biliary cirrhosis). We did not look for achlorhydria and did not find antral mucosal prolapse, which has been implicated in the pathogenesis of this condition. ${ }^{316}$

Surgery was not considered an option for most of the patients in this study because of the coexisting medical conditions. The aim of treatment was to control gastric bleeding. Other endoscopic techniques have been shown to be effective for this purpose. The heater probe has been successfully applied in 12 patients $^{13}$ and biopolar electrocoagulation has proved useful in some patients. ${ }^{12}$ Whether the Nd:YAG laser is superior to other modes of treatment remains to be determined. The advantages of laser seem to be that in a non-contact method of treatment, it reduces beeding from instrumental trauma, and by achieving deep penetration it may obliterate the large underlying submucosal veins better than other modes of treatment. ${ }^{\text {" }}$ The main disadvantage is its higher cost.

Our results show that laser photocoagulation is effective in eliminating the need for blood transfusion in patients with classic watermelon stomach. No recurrence was encountered during a 7 to 44 month follow up period and this is in accordance with other reports. ${ }^{89}$ In a large study with 13 patients, however, complete obliteration of the vascular lesion was not seen. ${ }^{11}$

The rather poor results in our patients with the honeycomb stomach could be attributed to the more diffuse and uneven distribution of the vascular lesions in this group. Possibly it represents a more advanced stage of the disease. On the other hand the columnar arrangement of the angioid streaks in watermelon stomach make it more suitable for laser treatment. It must be noted that one of three patients with the honey- comb stomach did gain significant improvement in terms of blood transfusion requirement after treatment and the differences we have noted may be a result of the small numbers in this study.

The safety of the procedure has been emphasised by other studies. ${ }^{5911}$ Perforation can be avoided by applying less energy at each site and by treating the patient over several sessions at 2-3 weekly intervals. Iatrogenic ulcers, which may be inevitable and were seen in two of our patients, will heal with a short course of an ulcer healing drug. Minor oozing during the procedure can be controlled by further laser treatment.

In conclusion, laser therapy seems to be safe and an effective alternative to surgery in patients with diffuse gastric antral vascular ectasia. The endoscopic pattern of the disease seems to influence the outcome of treatment. Further longterm studies are needed to assess this phenomenon and to compare the various endoscopic techniques that are available for its treatment.

1 Lee FI, Costello F, Flanagan N, Vasudef KS. Diffuse antral vascular ectasia. Gastrointest Endosc 1984; 30: 87-90.

2 Tovey FI. Gastric antral vascular ectasia: the watermelon stomach. Gastroenterology 1985; 88: 1293.

3 Jabbari M, Cherry R, Lough JO, Daly DS, Kinnear DG, Goresky CA. Gastric antral vascular ectasia: the watermelon stomach. Gastroenterology 1984; 87: 1165-70.

4 Chawla SK, Ramani K, Lo Presti P. The honeycomb stomach: coalesced gastric angiodysplasia. Gastrointest Endosc 1990; 36: 516-8.

5 Tsai HH, Smith J, Danesh BJ. Successful control of bleeding from gastric antral vascular ectasia (watermelon stomach) by from gastric antral vascular ectasia (waterme

6 Gardiner GW, Murray D, Prokipchuk ES. Watermelon stomach or antral gastritis. F Clin Pathol 1985; 38: 1317-8. 7 Heaton N. Aetiology of antral vascular malformation. $f R$ Soc Med 1986; 79: 434

8 Park RHR, Danesh BJZ, Upadhyay R, Howatson AG, Lee FD, Russell RI. Gastric antral vascular ectasia (watermelon stomach) - therapeutic options. Postgrad Med $\mathcal{f}$ 1990; 66: $720-3$.

9 Frager JD, Brandt LJ, Frank MS, Morecki R. Treatment of a patient with watermelon stomach using transendoscopic laser photocoagulation. Gastrointest Endosc 1988; 34: 134-7.

10 Bown SG, Swain CP, Storey DW, Collins C, Matthewson K, Salmon PR, et al. Endoscopic laser treatment of vascular anot gastrointestinal tract. Gut 1985; 26: $1338-48$.

11 Gostout CJ, Ahlquist DA, Radford CM, Viggiano TR, Bowyer BA, Balm RK. Endoscopic laser therapy for watermelon stomach. Gastroenterology 1989; 96: 1462-5.

12 Binmoeller KF, Katon RM. Bipolar electrocoagulation for watermelon stomach. Gastrointest Endosc 1990; 36: 399-402. 13 Petrini JL, Johnston JH. Heat probe treatment for antral vascular ectasia. Gastrointest Endosc 1989; 35: 324-8.

14 Rose JR. Endoscopic injection of alcohol for bleeding from gastroduodenal vascular anomalies. $B M F$ 1987; 295: 93-4.

15 Zuckerman GR, Cornette GL, Clouse RE. Upper gastrointestinal bleeding in patients with chronic renal failure. $A n n$ intestinal bleeding in patients 1985 ; 102: $588-92$.

16 Park RHR, Russell RI. Watermelon stomach. Br f Surg 1991; 78: 395-6. 